\title{
Simultaneous Electrical and Fluorescence Recording of HL-1 cells' Electrical Activity in Response to Extracellular Calcium Stimulation
}

\author{
Ondrej Svoboda ${ }^{1}$, Larisa Baiazitova ${ }^{1}$, Vratislav Cmiel $^{1}{ }^{\text {, Josef Skopalik }}{ }^{1}$, Ivo Provaznik ${ }^{1}$ \\ ${ }^{1}$ Department of Biomedical Engineering, Faculty of Electrical Engineering and Communication, \\ Brno University of Technology, Brno, Czech Republic
}

\begin{abstract}
In current cell tissue engineering and cardiology, beating models with behavior and properties similar to humans are necessary. The cardiac muscle HL-1 cells, whose genes have a parent with adult atrial myocytes, serve as a suitable model.

HL-1 cells were seeded on a 120-electrode microelectrode (MEA) chamber and transient transfection of Accelerated Sensor of Action Potentials 1 (ASAP1), a genetically encoded voltage indicator, was performed. Simultaneous electrical and optical recording of cardiac cell culture electrical activity was made when the cells started to produce spontaneous action potentials. Recording synchronization was made using TTL pulses.

Results showed that HL-1 cells start to produce asynchronous spontaneous action potentials $(-375 \pm 10 \mu \mathrm{V})$ when reaching $90 \%$ MEA chamber confluency and which become periodical addition of extracellular calcium $(-501 \pm 14 \mu \mathrm{V}, 2.1 \pm 1.0 \mathrm{~Hz})$. The ASAPl's fluorescent response reached up to $21 \pm 5 \% \Delta F / F$. The time constant between detection of electrical and fluorescent response ( $\left.\tau_{\text {e/o }}\right)$ was determined as $12 \pm 5 \mathrm{~ms}$.
\end{abstract}

\section{Introduction}

The beating in vitro models serve as important tools for understanding propagation of action potentials in the heart muscle. HL-1 mouse atrial cardiomyocytes [1], which express genes having a pattern with adult human atrial myocytes, give important information about the correlation of biochemical and electrophysiological aspects of the cardiac cells.

In cell population intracellular dynamic process studies, modern high throughput tools such as microelectrode arrays (MEAs) or large field of view (FOV) optical techniques have been increasingly applied in recent years.

The microelectrode array systems are based on extracellular recording of voltage fluctuations. The big advantages of these systems are long-term experiments, parallel recording from many channels at the same time and detection of subthreshold responses as well as trains of action potentials. Modern MEA setups might have up to thousands of active electrodes with an active diameter starting from units of $\mu \mathrm{m}$. Microelectrode systems are able to detect subthreshold potential changes as well as single and multiple action potentials [2,3]. There are some disadvantages of MEA systems, such as complicated preparation of MEA chambers or difficult interpretation of results because of measuring the second signal derivation. The crucial step in MEA experiments is choosing the design of substrate-integrated microelectrodes and coating procedure depending on cell type [4].

Optical techniques for monitoring intracellular ion exchange or protein dynamics use novel fluorescent voltage sensitive dyes or genetically encoded voltage indicators (GEVIs) [5]. GEVIs are promising tools for the tracking of spatiotemporal electrical activity in single cells and large tissue cultures. An ideal GEVI must provide fast kinetics, produce a high fluorescence response and ideally detect subthreshold membrane voltage changes.

The Accelerated Sensor of Action Potentials 1 (ASAP1) [6], is one of the latest GEVIs. Having circularly permuted green fluorescent protein (GFP) allows ASAP1 to track subthreshold membrane potential changes, single action potentials and fast trains of action potentials (up to $200 \mathrm{~Hz}$ ). ASAP1 has fast kinetics of about $2 \mathrm{~ms}$.

In this work, the unique combination of microelectrode array and fluorescence techniques was used to study simultaneous electrical and fluorescence recording of HL-1 cells' electrical activity in response to extracellular $\mathrm{Ca}^{2+}$ changes. The combination of modern techniques provides high spatiotemporal resolution thanks to the use of high sampling frequency $(25 \mathrm{kHz})$ of the MEA system and very fast kinetics (1-2 ms [6,7]) of ASAP1 sensor.

\section{Materials and methods}

\subsection{Cell culture}

The cardiac muscle HL-1 cells [1] (Sigma-Aldrich) were cultured in Claycomb medium (Sigma-Aldrich) supplemented with 10\% FBS (Sigma-Aldrich), $100 \mathrm{U} / \mathrm{ml}$ 
Penicillin/Streptomycin (Sigma-Aldrich), $\quad 0.1 \quad \mathrm{mM}$ Norepinephrine (Sigma-Aldrich), and $2 \mathrm{mM}$ L-Glutamine (Sigma-Aldrich) and passaged twice a week for up to ten passages according to the manufacturer's instructions. The cells were seeded on a microelectrode chamber for 24 hours before transfection at density $5 \times 104$ cells $/ \mathrm{ml}$.

\subsection{Microelectrode chambers}

The one hundred and twenty electrode 120MEA100/30iR-ITO-gr microelectrode chambers (Multi Channel Systems MCS GmbH) with $12 \times 12$ electrode layout (Figure 1) were coated at $37^{\circ} \mathrm{C}$ with $5 \mu \mathrm{g} / \mathrm{ml}$ (SigmaAldrich) fibronectin dissolved in $0.02 \%$ gelatin from bovine skin (Sigma-Aldrich) at least one hour before cell seeding. The MEA chambers were cleaned and sterilized before use as described earlier [4].

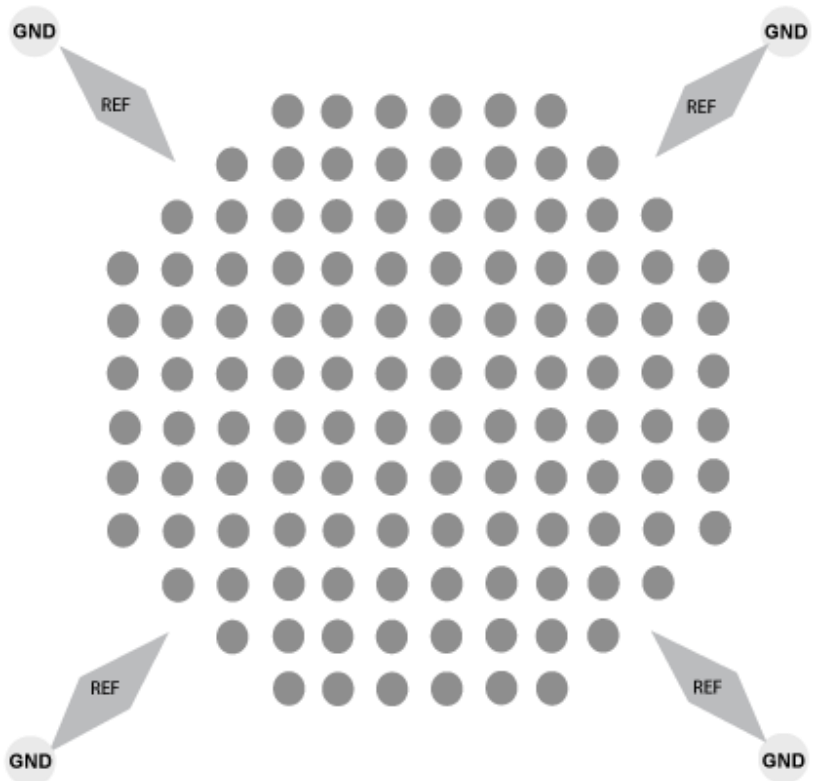

Figure 1: The one hundred and twenty electrode MEA chamber layout (Multi Channel Systems MCS GmbH). $30 \mu \mathrm{m}$ electrode diameter, $100 \mu \mathrm{m}$ electrode spacing.

\subsection{Transfection}

The transient transfection [8,9] of HL-1 cells with ASAP1 DNA plasmid (pcDNA3.1/Puro-CAG-ASAP1, Addgene, $7.5 \mathrm{kpb})$ was made using linear polyethyleneimine (PEI MAX 40K, Polysciences) on cells cultured for 24 hours on the microelectrode chamber. The transfection complex was synthetized in $65 \mu 1150 \mathrm{mM}$ $\mathrm{NaCl}$. The ASAP1's plasmid DNA was dissolved in $\mathrm{NaCl}$ at final concentration $2.25 \mu \mathrm{g} \cdot \mathrm{ml}^{-1}$ followed by the addition of PEI at final concentration $6.00 \mu \mathrm{g} \cdot \mathrm{ml}^{-1}$. The transfection mix was then incubated for 10 minutes at room temperature. The incubation sample was then filled up to $750 \mu \mathrm{l}$ with culture media. Afterwards, the transfection mixture was transferred onto the microelectrode chamber and cultured at $37{ }^{\circ} \mathrm{C}$ and $5 \% \mathrm{CO}_{2}$ until fully confluent (approximately 24-48 hours). Fresh culture media was replaced 8 hours post-transfection and then every 24 hours.

\subsection{Electrical and fluorescence recording}

The electrical recording with USB MEA2100-System from Multi Channel Systems MCS GmbH, which contained 120 recording electrodes, was combined with an ultrasensitive fast Andor iXon3 860 EMCCD backilluminated camera (experimental design is shown in Figure 2). MEA2100-System was set to record with $25 \mathrm{kHz}$ sampling frequency and $\pm 10 \mathrm{mV}$ input range with no electrical stimulation. Video sequence was acquired at the highest camera sampling ratio. The recording synchronization between the MEA2100-System and the Andor iXon3 was made using TTL pulses.

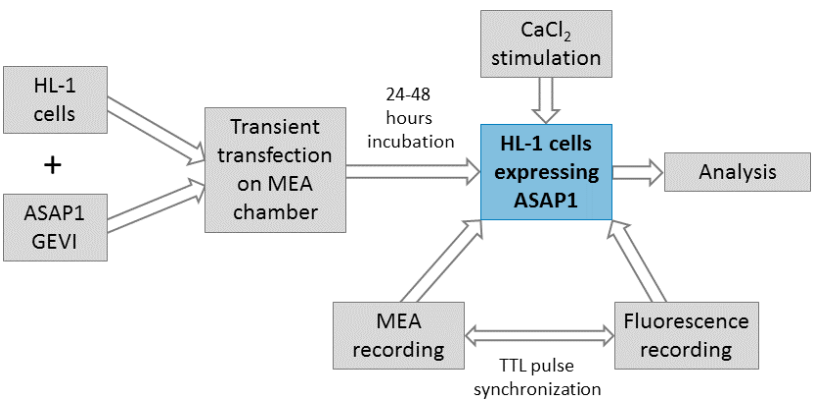

Figure 2: Experimental setup for electrical and optical recording of HL-1 electrical activity.

Calcium stimulation of HL-1 cells was made by adding the $\mathrm{CaCl}_{2}$ (Braun) solution. Three final concentrations of $\mathrm{Ca}^{2+}$ in Claycomb medium $(4.5,9.0$ and $22.5 \mu \mathrm{M})$ were studied (Table 1).

At the beginning of each experiment, a 60-second baseline was recorded to study any HL-1 spontaneous activity. Thereafter, addition of the desired amount of $\mathrm{CaCl}_{2}$ was followed by 120 seconds of synchronous electrical and fluorescent recording.

\subsection{Electrical and fluorescence response analysis}

Records were analysed for points of amplitude and frequency of signals obtained ASAP1's fluorescence response. The unique electrical/optical time constant $\tau_{\mathrm{e} / \mathrm{o}}$, which describes the lag between electrical and fluorescence response, was defined as well.

Electrical records were analyzed using Multi-Channel Analyzer (Multi Channel Systems MCS GmbH) software. For the fluorescent response analysis, Matlab (Mathworks) software was used. The final time constant analysis was 
performed in Matlab and OriginPro 2016 (OriginLab) software.

\section{Results and discussion}

In this section we present the results of simultaneous electrical and optical recording of HL-1 cells' electrical activity. The 120-electrode TiN microelectrode array recording was combined with transient polyethyleneimine transfection of ASAP1 DNA plasmid. The properties of ASAP1 were confirmed while expressed in HEK293 cells $[6,10]$ using linear polyethyleneimine transfection. However, its application is very extensive; it has been expressed in neural networks [6], or Xenopus laevis oocytes [5].

The ASAP1 expression was confirmed by fluorescence microscopy (Figure 3) when HL-1 cells had reached full confluency. The electrical activity of the cells was studied by MEA for any detectable electrical response continuously from transfection in a 12-hour time period.

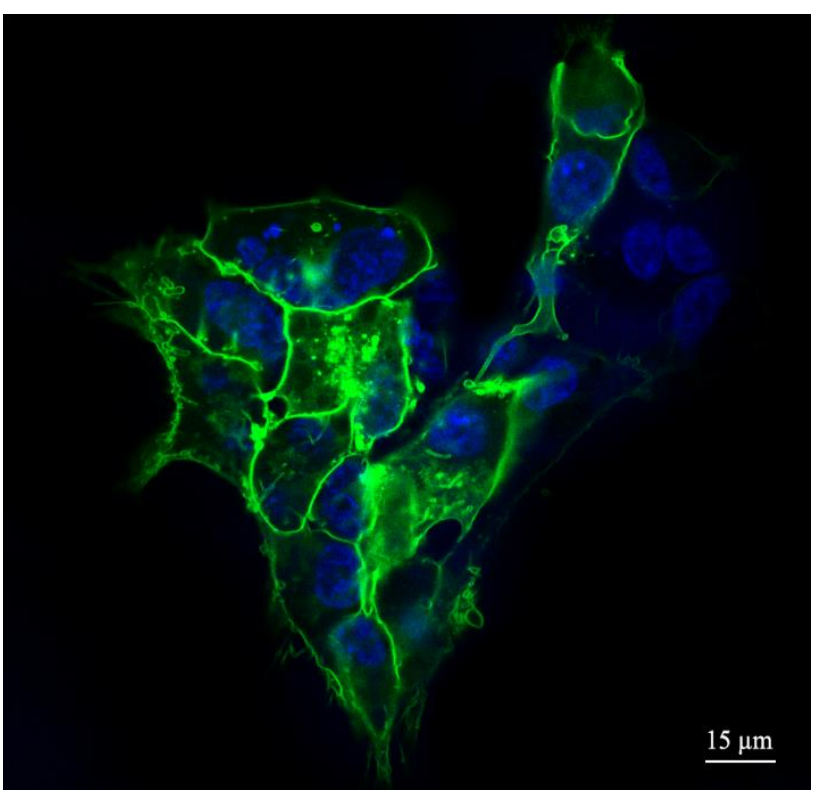

Figure 3: HL-1 cells expressing ASAP1 plasmid (ex. 395 $\mathrm{nm} / \mathrm{em} .475 \mathrm{~nm}$ ); nuclei stained with Hoechst 33342 (ex. $350 \mathrm{~nm} / \mathrm{em} .461 \mathrm{~nm})$.

Analysis of recordings showed that cells start to produce detectable spontaneous action potentials with no periodicity when they have reached $90 \%$ confluency of the MEA chamber (Figure 4). These action potentials had $-375 \pm 10$ $\mu \mathrm{V}$ amplitude $(\mathrm{n}=50$ cells). The electrical activity became periodical after application of $\mathrm{CaCl}_{2}$ on the fully confluent MEA chamber. The amplitude of action potentials decreased to $-501 \pm 14 \mu \mathrm{V}$ after application of $22.5 \mu \mathrm{M}$ $\mathrm{CaCl}_{2}$.

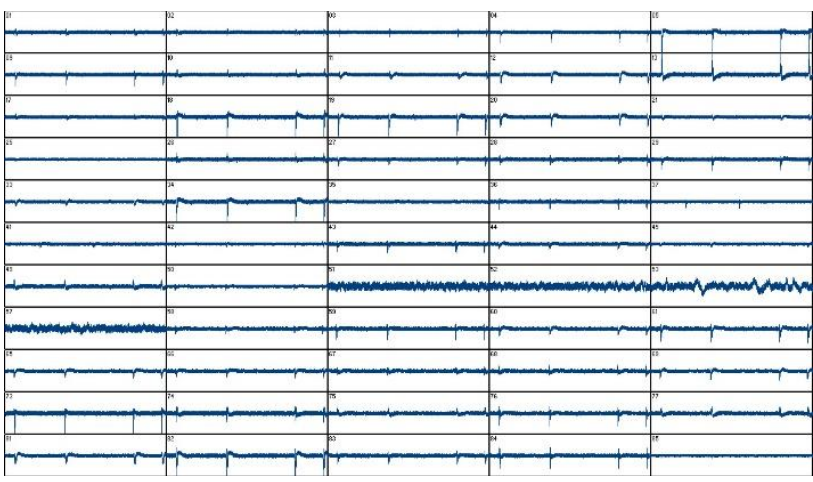

Figure 4: HL-1 electrical response on a 120MEA100/30iRITO-gr microelectrode chamber recorded by USB MEA2100-System (Multi Channel Systems MCS GmbH).

The ASAP1 fluorescent response followed depolarization and produced detectable fluorescent changes of up to $21 \pm 5 \% \Delta \mathrm{F} / \mathrm{F}$ (Table 1). The time between detection of the maximal positive value of action potential and maximal ASAP1's fluorescence response defines time constant $\tau_{e / o}$, which had a constant value $12 \pm 5 \mathrm{~ms}$ during the analysis.

Table 1. $\mathrm{CaCl}_{2}$ concentration and corresponding HL-1 responses. Results are presented as mean $\pm \mathrm{SD}(\mathrm{n}=50$ cells).

\begin{tabular}{lll}
\hline $\begin{array}{l}\mathrm{CaCl}_{2} \\
\text { concentration } \\
(\mu \mathrm{M})\end{array}$ & $\begin{array}{l}\mathrm{HL}-1 \text { electrical } \\
\text { response } \\
(\mu \mathrm{V})\end{array}$ & $\begin{array}{l}\text { Normalized } \\
\text { HL-1 fluorescent } \\
\text { response } \\
(\%)\end{array}$ \\
\hline 0.0 & $-375 \pm 10$ & $21 \pm 5$ \\
4.5 & $-406 \pm 9$ & $21 \pm 5$ \\
9.0 & $-459 \pm 13$ & $21 \pm 5$ \\
22.5 & $-501 \pm 14$ & $21 \pm 5$ \\
\hline
\end{tabular}

\section{Conclusions}

The method for synchronous electrical and optical recording of HL-1 cell culture activity is presented here. The microelectrode system, which uses extracellular recording of membrane potential, was used jointly with genetically encoded voltage indicator ASAP1. The action potentials were detected from $90 \%$ confluency of a 100/30iR-ITO-gr microelectrode chamber. The amplitude of perceptible spontaneous action potentials had $-375 \pm 10 \mu \mathrm{V}$ and became periodical after extracellular application of $\mathrm{Ca}^{2+}$ with amplitude $-434 \pm 45 \mu \mathrm{V}$. When reaching the final concentration $22.5 \mu \mathrm{M} \mathrm{Ca}^{2+}$, the APs frequency reached $2.1 \pm 1.0 \mathrm{~Hz}$ and amplitude decreased to $-501 \pm 14 \mu \mathrm{V}$. The ASAP1 produced a fluorescence response of up to $21 \pm 5 \% \Delta \mathrm{F} / \mathrm{F}$, which corresponds to APs propagation on the cell culture. The time constant between electrical and optical detection of action potentials was 
determined as $12 \pm 5 \mathrm{~ms}$. The main advantage of this study is a more complex view of HL-1 cell culture electrical activity.

\section{Acknowledgements}

This paper has been supported by a grant from the Czech Science Foundation No. GA18-24089S.

\section{References}

[1] Claycomb WC, Lanson NAJ, Stallworth BS, Egeland DB, Delcarpio JB, Bahinski A, et al. HL-1 cells: a cardiac muscle cell line that contracts and retains phenotypic characteristics of the adult cardiomyocyte. Proc Natl Acad Sci U S A. 1998 Mar;95(6):2979-84.

[2] Spira ME, Hai A. Multi-electrode array technologies for neuroscience and cardiology. Nat Nano [Internet]. 2013 Feb;8(2):83-94. Available from: http://dx.doi.org/10.1038/nnano.2012.265

[3] Plenz D, Stewart C V., Shew W, Yang H, Klaus A, Bellay T. Multi-electrode Array Recordings of Neuronal Avalanches in Organotypic Cultures. J Vis Exp. 2011;(54):1-7.

[4] Svoboda O, Skopalik J, Baiazitova L, Gabrielova E, Cmiel V, Provaznik I, et al. An evaluation of different coatings for TiN microelectrode chambers used for neonatal cardiomyocytes. In: 2016 Computing in Cardiology Conference (CinC). 2016. p. 365-8.

[5] Lee EEL, Bezanilla F. Biophysical Characterization of Genetically Encoded Voltage Sensor ASAP1: Dynamic Range Improvement. Biophys J [Internet]. 2017;113(10):2178-81. Available from: http://www.sciencedirect.com/science/article/pii/S0006 349517311335

[6] St-Pierre F, Marshall JD, Yang Y, Gong Y, Schnitzer MJ, Lin MZ. High-fidelity optical reporting of neuronal electrical activity with an ultrafast fluorescent voltage sensor. Nat Neurosci [Internet]. 2014;17(6):884-9. Available from: http://www.ncbi.nlm.nih.gov/pubmed/24755780

[7] Svoboda O, Skopalik J, Baiazitova L, Cmiel V, Potocnak T, Provaznik I, et al. DNA Intracellular Delivery into 3T3 Cell Line Using Fluorescence Magnetic Ferumoxide Nanoparticles. 2019;

[8] Longo PA, Kavran JM, Kim M-S, Leahy DJ. Transient Mammalian Cell Transfection with Polyethylenimine (PEI). Methods Enzymol [Internet]. 2013;529:227-40. Available from: http://www.ncbi.nlm.nih.gov/pmc/articles/PMC401232 $1 /$

[9] Ehrhardt C, Schmolke M, Matzke A, Knoblauch A, Will C, Wixler V, et al. Polyethylenimine, a cost-effective transfection reagent. Signal Transduct [Internet]. 2006 Jun;6(3):179-84. Available from: http://dx.doi.org/10.1002/sita.200500073
[10] Svoboda O, Fohlerova Z, Baiazitova L, Mlynek P, Samouylov K, Provaznik I, et al. Transfection by Polyethyleneimine-Coated Magnetic Nanoparticles: Fine-Tuning the Condition for Electrophysiological Experiments. J Biomed Nanotechnol. 2018 Aug;14(8):1505-14.

Address for correspondence.

Larisa Baiazitova

Department of Biomedical Engineering Faculty of Electrical Engineering and Communication Brno University of Technology

Technicka 3082/12

61600 Brno

Czech Republic

baiazitova@feec.vutbr.cz 